\title{
Patterns of Use of Smartphone-Based Interventions Among Latina Breast Cancer Survivors: Secondary Analysis of a Pilot Randomized Controlled Trial
}

Sharon H Baik ${ }^{1,2}$, PhD; Laura B Oswald ${ }^{1,3}$, PhD; Joanna Buscemi ${ }^{4}, \mathrm{PhD}$; Diana Buitrago ${ }^{1}$, BA; Francisco Iacobelli ${ }^{5}$, $\mathrm{PhD}$; Alejandra Perez-Tamayo ${ }^{6}$, MD; Judith Guitelman ${ }^{7}$; Frank J Penedo ${ }^{8}$, PhD; Betina Yanez ${ }^{1}, \mathrm{PhD}$

\author{
${ }^{1}$ Department of Medical Social Sciences, Northwestern University Feinberg School of Medicine, Chicago, IL, United States \\ ${ }^{2}$ Department of Supportive Care Medicine, City of Hope, Duarte, CA, United States \\ ${ }^{3}$ Department of Health Outcomes and Behavior, Moffitt Cancer Center, Tampa, FL, United States \\ ${ }^{4}$ Department of Psychology, DePaul University, Chicago, IL, United States \\ ${ }^{5}$ Department of Computer Science, Northeastern Illinois University, Chicago, IL, United States \\ ${ }^{6}$ Department of Surgery, University of Illinois at Chicago, Chicago, IL, United States \\ ${ }^{7}$ ALAS-WINGS, The Latina Association for Breast Cancer, Chicago, IL, United States \\ ${ }^{8}$ Department of Psychology, University of Miami, Coral Gables, FL, United States
}

\section{Corresponding Author:}

Sharon H Baik, PhD

Department of Supportive Care Medicine

City of Hope

1500 E Duarte Rd

Duarte, CA, 91010

United States

Phone: 16262564673

Email: $\underline{\text { shbaik@coh.org }}$

\section{Abstract}

Background: Latina breast cancer survivors experience poorer health-related quality of life (HRQoL), greater symptom burden, and more psychosocial needs compared to non-Latina breast cancer survivors. eHealth platforms such as smartphone apps are increasingly being used to deliver psychosocial interventions to cancer survivors. However, few psychosocial eHealth interventions have been developed specifically for Latina breast cancer survivors. Further, little is known about how Latinas, in general, engage with eHealth interventions and whether specific participant characteristics are associated with app use in this population. We evaluated the use of 2 culturally informed, evidence-based smartphone apps for Latina breast cancer survivors - one that was designed to improve HRQoL and reduce symptom burden (My Guide) and the other to promote healthy lifestyle behaviors (My Health).

Objective: The objectives of our study were to explore the patterns of use of the My Guide intervention app and My Health attention-control app among Latina breast cancer survivors.

Methods: Eighty Latina breast cancer survivors were randomized to use the My Guide or My Health app for 6 weeks. Assessments were collected at baseline (T1), immediately after the 6-week intervention (T2), and 2 weeks after T2 (T3). Specific study outcomes included subdomains of HRQoL, symptom burden, cancer-specific distress, cancer-relevant self-efficacy, and breast cancer knowledge.

Results: On average, participants used their assigned app for more than 1 hour per week. Sociodemographic or psychological characteristics were not significantly associated with app use, except for employment status in the My Health group. Content related to common physical and emotional symptoms of breast cancer survivors as well as recommendations for nutrition and physical activity were most frequently accessed by My Guide and My Health participants, respectively. Lastly, clinically meaningful improvements were demonstrated in breast cancer well-being among low app users (ie, <60 minutes of use/week) of My Guide and social well-being among high app users (ie, $\geq 60$ minutes of use/week) of My Health.

Conclusions: The favorable rates of participant use across both apps suggest that Latina breast cancer survivors are interested in the content delivered across both My Guide and My Health. Furthermore, since sociodemographic variables, excluding 
employment status, and baseline HRQoL (psychological variable) were not related to app use, My Guide and My Health may be accessible to diverse Latina breast cancer survivors.

Trial Registration: ClinicalTrials.gov NCT03645005; https://clinicaltrials.gov/ct2/show/NCT03645005

(JMIR Cancer 2020;6(2):e17538) doi: 10.2196/17538

\section{KEYWORDS}

breast cancer; cancer survivorship; Hispanics/Latinas; eHealth; psychosocial intervention; mobile phone

\section{Introduction}

Breast cancer is the most prevalent cancer and the leading cause of cancer-related deaths among Latina women in the United States, with an estimated 24,000 new cases diagnosed and 3200 deaths expected annually [1]. Currently, there are more than 200,000 Latina breast cancer survivors living in the United States [2] and this number is expected to continue increasing. Latina breast cancer survivors experience disparities in survivorship outcomes compared to non-Latina breast cancer survivors, including lower health-related quality of life (HRQoL), greater symptom burden, and greater unmet psychosocial needs [3-11]. These factors are associated with poorer health outcomes [12,13] and must be addressed to promote optimal long-term survivorship for Latina breast cancer survivors. However, Latinas are underrepresented in cancer research $[9,14]$ and although a number of psychosocial interventions have demonstrated efficacy for improving HRQoL outcomes among breast cancer survivors [13,15,16], few interventions have been developed specifically for Latina breast cancer survivors $[3,9,17]$. Further, psychosocial interventions may be more effective when culturally and linguistically tailored to a particular racial/ethnic group [18]. Specifically, some Latina cultural values and beliefs (eg, familism, fatalism, Marianismo) $[19,20]$ may impact health behaviors and outcomes and thus should be considered as intervention approaches that may need to be adapted. In general, culturally adapted interventions have demonstrated moderate-to-large effects [21].

eHealth platforms are increasingly being used to deliver psychosocial interventions to general cancer survivors and have demonstrated positive effects related to psychosocial outcomes and lifestyle behaviors [22,23]. Research shows that Latinas own smartphones and surf the internet using their mobile devices at similar or higher rates than other racial/ethnic groups [24]. Therefore, smartphone-based apps provide an innovative opportunity to implement culturally informed, technology-based, and evidence-based psychosocial interventions for this population to overcome barriers to accessing care and resources and reduce participant and provider burden, and they are more easily scalable than traditional in-person intervention delivery methods. Prior research has demonstrated that physical and psychological outcomes in eHealth interventions are influenced by different measures of adherence or usage (eg, number of logins, modules completed, time spent on app) [25], and higher use of web-based interventions among cancer survivors is associated with specific user characteristics such as having low social support and high illness burden or working and receiving radiation therapy $[26,27]$. However, little is known about how Latina breast cancer survivors engage with eHealth interventions or what participant characteristics are associated with eHealth use in this population.

Our team developed and evaluated 2 culturally informed and evidence-based smartphone apps for Latina breast cancer survivors in a 6-week pilot randomized controlled trial. The intervention app, My Guide, was designed to improve HRQoL, reduce symptom burden, and reduce cancer-specific distress, and the attention-control app, My Health, was designed to promote general health and healthy lifestyle behaviors [28]. Results demonstrated that Latina breast cancer survivors across both study conditions reported temporary decreases in symptom burden and improved breast cancer well-being over time, although there were no differential effects between the apps [29]. The primary objective of this secondary analysis was to report patterns of participant use of the My Guide and My Health smartphone apps over the course of the pilot randomized controlled trial. More specifically, we provide data on the frequency of specific domains accessed within the My Guide and My Health apps and the average total duration of app use. Determining the most commonly accessed and viewed topics is clinically important, as it can help inform future refinement of the study apps as well as in-person psychosocial interventions designed to address the most important cancer topics for this understudied population. Furthermore, given the limited research in this area, we explored whether participant characteristics were related to app use as well as whether app use was related to study outcomes over time.

\section{Methods}

\section{Study Participants and Design}

Women were eligible to participate in the study if they were diagnosed with nonmetastatic stage 0 -III breast cancer, had completed active treatment for breast cancer (excluding endocrine therapy), were within 2-24 months of completing treatment, were at least 21 years old, able to read and speak English or Spanish, and able to provide informed consent. Women were excluded if they had a diagnosis of another cancer, serious psychiatric disorder (eg, bipolar disorder, substance dependence), or life-threatening illness (eg, end-stage kidney disease). Study recruitment included advertisements and physician referrals from 2 academic medical centers in the Chicago area and ALAS-WINGS, a community-based organization that serves Latina women with breast cancer.

Eligible participants provided informed consent and completed a sociodemographic questionnaire and psychosocial assessment at baseline (T1) in their preferred language (English or Spanish). Follow-up assessments were completed at postintervention (6 weeks from baseline, T2) and 2 weeks after the intervention ( 8 
weeks from baseline, T3). After providing informed consent, participants were randomized 1:1 to receive either My Guide or My Health smartphone-based app for 6 weeks, and participants were instructed to use their assigned app for 2 hours per week. Participants continued to have access to their assigned app from T2 to T3, but we did not analyze their usage data (ie, time spent on app, webpages clicked), and reinforcement messages or calls for adherence were not provided during this time.

App use for My Guide and My Health was supported by trained bilingual telecoaches using a stepped-care approach. Specifically, telecoaching calls were provided to all participants who focused on enhancing their adherence to using their assigned app and addressed any issues or barriers to using the app. All participants received telecoaching calls during the first 2 weeks as well as during the final sixth week. Subsequent telecoaching calls during the third, fourth, and fifth weeks were only made to participants who did not use their app for at least 90 minutes per week (threshold), whereas reinforcing text messages were sent to participants who used their app for 90 minutes or more. Telecoaching was brief ( 15 minutes) and delivered using motivational interviewing and goal setting to encourage app use during the study period. Telecoaching calls were audio-recorded and reviewed weekly by a licensed clinical psychologist to ensure fidelity. A threshold of 90 minutes of weekly app use was determined by other web-based studies that also focused on the delivery of symptom management for patients with cancer [30,31]. On average, My Guide and My Health app users received 3.72 and 4.10 telecoaching calls, respectively, over the 6-week study period. Further details of the study design, development, and protocol are published elsewhere [28]. All study procedures and assessments were approved by the Institutional Review Board at Northwestern University prior to study recruitment.

\section{Study Apps}

Both smartphone apps were developed by the Center for Behavioral Intervention Technologies at Northwestern University Feinberg School of Medicine [28]. The content for My Guide and My Health was culturally informed by Latina cultural values and beliefs (eg, familism, fatalism, Marianismo) $[19,20]$ and developed in collaboration with the Latina Breast Cancer Association, a community partner. Both apps were developed in English and Spanish so that they were each delivered in the participant's preferred language, and all content was available in audio format to address concerns about low literacy.

The My Guide app was designed to improve HRQoL and reduce symptom burden among Latina breast cancer survivors. The intervention content was based on models of stress and coping [32-34], prior research on psychosocial adjustment to cancer $[35,36]$, and preliminary results suggesting that self-efficacy in patient-provider communication, cancer-related knowledge, stress management, and social support can improve HRQoL and symptom burden among Latina breast cancer survivors [3,19,35,37-39]. Specifically, the content focused on improving psychosocial adaptation during cancer survivorship, coping with side effects from treatment, stress management, social support, and breast cancer-related knowledge. My Health, the attention-control app, was designed to improve health-promoting behaviors and provided general recommendations for nutrition and exercise, prevention of common chronic illnesses, and other healthy lifestyle behaviors. The control content was based on similar studies of psychosocial interventions among cancer survivors with active controls [31]. Each app comprised of 6 content domains or distinct topic areas (see Multimedia Appendix 1 for a brief summary of each domain and its related content) as well as a media component ("Listen and Learn") consisting of videos and audio recordings that were incorporated and complemented information throughout the domains. For example, My Guide included informational videos from experts on breast health and common side effects, stories from other cancer survivors, and audio programs of relaxation exercises, whereas My Health included videos about healthy eating and lifestyle behaviors. Both apps were designed to be self-guided, such that participants had complete access to all the domains and could freely access any content based on their interest, at their own pace, and at any time.

\section{Measures}

All measures were provided in the participants' preferred language of English or Spanish.

\section{Sociodemographic and Cancer-Specific Characteristics}

At baseline, participants completed a self-report sociodemographic questionnaire, which included information such as age, ancestry (Mexican vs other), language preference, highest education, annual household income, employment status, and marital status. Additionally, participants self-reported cancer-specific characteristics, which were verified by medical chart review, including stage of disease and type of treatment(s) received.

\section{App Use}

Both apps tracked participant use in minutes per week throughout the study period, from which the total 6-week app use was computed by summing the 6 weekly use times. Average weekly use was also computed to help with interpretation (ie, total app use in minutes divided by 6 weeks). Additionally, all actions taken within each app (ie, click data) were tracked for each participant. The log files included the following data for each action: participant information (ie, unique identification number), app information (ie, English vs Spanish, My Guide vs My Health), and timestamp (date and time) of links clicked. From this data, we extracted information related to the frequency of visits to each webpage (links) in the app for each participant. We were then able to determine the most and least accessed content within each app.

\section{HRQoL}

The 36-item Functional Assessment of Cancer Therapy-Breast (FACT-B) [40] measures 5 HRQoL subdomains, namely, physical well-being, emotional well-being, social well-being, functional well-being, and additional breast cancer-related concerns. Respondents were asked to rate their level of agreement with statements regarding concerns over the past 7 days by using a 5-point Likert-type scale from 0 (not at all) to 4 (very much). Higher scores indicate better domain-specific 
well-being. The FACT-B has been validated in Spanish [41] and is extensively used among patients with breast cancer [40,41]. Additionally, at baseline, participants completed the rapid version of the Functional Assessment of Cancer Therapy-General (FACT-G7), a valid and reliable 7-item measure of the most prominent HRQoL concerns among cancer survivors [42].

\section{Symptom Burden}

The 25-item Breast Cancer Prevention Trial questionnaire [43] consists of 25 common breast cancer-related symptoms. Respondents rated their level of discomfort with each symptom during the past 4 weeks by using a 5-point Likert-type response scale from 0 (not at all) to 4 (extremely). Total scores range from 0 to 100, with higher scores indicating higher breast cancer symptom burden.

\section{Cancer-Specific Distress}

The 15-item Impact of Events Scale [44] assesses the frequency of intrusive thoughts or avoidance following a stressful event, specifically cancer, and uses a response scale with 4 points, that is, 0 (not at all), 1 (rarely), 3 (sometimes), and 5 (often). Total scores range from 0 to 75 , with higher scores indicating greater distress. The Impact of Events Scale has also been validated in Spanish [45].

\section{Cancer-Relevant Self-Efficacy}

The 12-item Communication and Attitudinal Self-Efficacy scale for cancer (CASE-cancer) [46] assesses one's self-efficacy in emotional resilience, communication, and information seeking in the context of a cancer diagnosis. Respondents rated their confidence using various skills on a 4-point response scale from 1 (not at all) to 4 (extremely). Higher values indicate greater self-efficacy with possible values ranging from 12 to 48 . Previous studies have used the CASE-cancer with Latina breast cancer survivors $[46,47]$.

\section{Breast Cancer Knowledge}

The 16-item Knowledge about Breast Cancer questionnaire assesses general knowledge about breast cancer diagnosis and treatment. Respondents were asked to answer true or false to 16 statements. Correct responses were first summed and then divided by the total number of responses to compute an average correct response score. Total scores range from 0 to16, with higher scores reflecting better breast cancer knowledge [48]. This questionnaire was previously tested with a large sample of Spanish-speaking Latina breast cancer survivors [48] and used in the initial My Guide pilot study [28].

\section{Data Analyses Plan}

We conducted linear regression analyses to evaluate whether sociodemographic characteristics (ie, age, language preference, education level, total household income, ancestry, marital status, employment status) or baseline psychological variables (ie, FACT-G7 baseline score) were related to total app use. Clinical significance was determined with $P<.05$, and marginal associations were reported with $P<.10$. Frequencies of total clicks (ie, pages viewed) were calculated for each domain and subdomain within each app, and we used descriptive statistics to describe notable patterns in click-level app use. Given the exploratory nature of these analyses and underpowered sample size to conduct inferential statistics within subgroups of app users, we focused on descriptive statistics to characterize study outcomes across time by high (ie, $\geq 60$ minutes per week) versus low (ie, <60 minutes per week) use of the My Guide or $M y$ Health app. Established minimally important differences for the FACT-B subscales (ie, a minimum of 2 points) [49-51] were used to characterize changes in the HRQoL subdomains across time. The established minimally important differences are not available for other study outcomes.

\section{Results}

\section{Sample Characteristics}

Latina breast cancer survivors $(\mathrm{N}=80)$ were enrolled and randomized to use My Guide or My Health. However, 2 participants (one from each condition) were withdrawn due to technical issues, resulting in a total of 78 Latina breast cancer survivors analyzed. Table 1 presents the demographic characteristics of the sample. Overall, participants had a mean (SD) age of 52.54 (11.36) years, and most were born outside the United States $(55 / 78,71 \%)$, of Mexican ancestry (50/78, $64 \%$ ), and with Spanish as their preferred language (50/78, $64 \%$ ). There were no significant differences in the sociodemographic and clinical characteristics between study conditions $(P>.05)$. 
Table 1. Baseline sociodemographic and clinical characteristics.

\begin{tabular}{|c|c|c|c|}
\hline Characteristics & Full sample (n=78) & My Guide app users $(\mathrm{n}=39)$ & My Health app users $(\mathrm{n}=39)$ \\
\hline \multicolumn{4}{|l|}{ Age (years) } \\
\hline Mean (SD) & $52.54(11.36)$ & $53.52(11.25)$ & $51.55(11.53)$ \\
\hline Range & $29-75$ & $33-73$ & $29-75$ \\
\hline \multicolumn{4}{|l|}{ Language preference, $\mathbf{n}(\%)$} \\
\hline English & $28(36)$ & $14(36)$ & $14(36)$ \\
\hline Spanish & $50(64)$ & $25(64)$ & $25(64)$ \\
\hline Mexican ancestry, n (\%) & $50(64)$ & $25(64)$ & $25(64)$ \\
\hline Born in the United States, $\mathrm{n}(\%)$ & $23(30)$ & $14(36)$ & $9(23)$ \\
\hline High school education or less, $\mathrm{n}(\%)$ & $42(54)$ & $23(59)$ & $19(49)$ \\
\hline Annual household income $<$ US $\$ 25,000, \mathrm{n}(\%)$ & $41(53)$ & $23(59)$ & $18(46)$ \\
\hline Employed, n (\%) & $34(44)$ & $17(44)$ & $17(44)$ \\
\hline Married or partnered, $\mathrm{n}(\%)$ & $50(64)$ & $23(59)$ & $27(69)$ \\
\hline \multicolumn{4}{|l|}{ Stage of breast cancer, $n(\%)$} \\
\hline 0 & $3(4)$ & $2(5)$ & $1(3)$ \\
\hline $\mathrm{I}$ & $28(36)$ & $14(36)$ & $14(36)$ \\
\hline II & $32(41)$ & $16(41)$ & $16(41)$ \\
\hline III & $11(14)$ & $5(13)$ & $6(15)$ \\
\hline Did not report & $4(5)$ & $2(5)$ & $2(5)$ \\
\hline Received chemotherapy, n (\%) & $45(58)$ & $21(54)$ & $24(62)$ \\
\hline Received radiation therapy, $\mathrm{n}(\%)$ & $55(71)$ & $28(72)$ & $27(69)$ \\
\hline FACT-G7 ${ }^{\mathrm{a}}$ baseline score, mean (SD) & $19.947(4.98)$ & $20.053(5.17)$ & $19.842(4.86)$ \\
\hline
\end{tabular}

${ }^{\mathrm{a}}$ FACT-G7: Functional Assessment of Cancer Therapy-General 7 items.

\section{App Use}

Latina breast cancer survivors used their assigned smartphone app for mean (SD) time of 478.15 (385.84) minutes over the 6 -week study period. The mean (SD) weekly app use did not differ between My Guide (86.58 [66.08] minutes per week) and
My Health (72.80 [62.57] minutes per week, $\left.\mathrm{t}_{76}=-0.95 ; P=.34\right)$. See Table 2 for the total app use for each week, average weekly use, and total use over the 6-week study period. A notable pattern across both apps is the reduced weekly app use during the third week followed by an increase during the subsequent week, presumably after receiving more telecoaching.

Table 2. Total time and average time of app usage.

\begin{tabular}{|c|c|c|c|c|}
\hline \multirow[t]{2}{*}{ Weeks } & \multicolumn{2}{|c|}{ My Guide app users (n=39), time (minutes) } & \multicolumn{2}{|c|}{ My Health app users ( $\mathrm{n}=39)$, time (minutes) } \\
\hline & Mean (SD) & Range & Mean (SD) & Range \\
\hline Week 1 & $95.97(102.72)$ & $0-431$ & $65.74(73.99)$ & $0-400$ \\
\hline Week 2 & $90.51(93.80)$ & $0-426$ & $86.33(105.45)$ & $0-376$ \\
\hline Week 3 & $69.03(69.87)$ & $0-250$ & $66.79(72.89)$ & $0-251$ \\
\hline Week 4 & $87.26(81.30)$ & $0-350$ & $73.26(74.46)$ & $0-264$ \\
\hline Week 5 & $91.13(82.30)$ & $0-311$ & $77.69(89.06)$ & $0-372$ \\
\hline Week 6 & $85.59(85.51)$ & $0-318$ & $67.00(81.40)$ & $0-378$ \\
\hline Total usage (weeks 1-6) & $519.49(396.51)$ & $0-1612$ & $436.82(375.43)$ & $0-1551$ \\
\hline Average weekly usage & $86.58(66.08)$ & $0-269$ & $72.80(62.57)$ & $0-259$ \\
\hline
\end{tabular}

\section{Predictors of App Use}

There were no significant relationships between the sociodemographic characteristics or baseline HRQoL and total app use (all $P>.10$ ), except for employment status. Specifically, for My Health, participants who were employed used the app 
for a lesser duration than those who were unemployed $(\beta=-.33$; $P=.04)$.

Table 3. Total number of clicks for each domain within each app.

\section{Patterns of App Use}

Table 3 presents the click-level data for each domain in each app. Click-level data for each subdomain is presented in Multimedia Appendix 2.

\begin{tabular}{ll}
\hline App type, domains & $\mathrm{n}(\%)$, Values \\
\hline My Guide app (n=6368) & $1731(27.18)$ \\
Managing My Emotions & $963(15.12)$ \\
Managing My Symptoms & $784(12.31)$ \\
Managing My Health & $318(4.99)$ \\
Breast Cancer Medications & $608(9.55)$ \\
Family and Friends & $685(10.76)$ \\
Community and Everyday Support & $1279(20.08)$ \\
Listen and Learn (Media) & \\
My Health app (n=7167) & $1339(18.68)$ \\
Diet and Nutrition part 1 & $1527(21.31)$ \\
Diet and Nutrition part 2 & $1391(19.41)$ \\
Exercise & $573(7.99)$ \\
Preventing Diabetes and Heart Disease & $929(12.96)$ \\
Lifestyle Behaviors & $999(13.94)$ \\
Doctor's Recommendations & $409(5.71)$ \\
Media & \\
\hline
\end{tabular}

\section{My Guide App}

Over the 6-week study period, My Guide participants clicked on a total of 6368 links or webpages of intervention content within the app. Participants most frequently accessed content within the Managing My Emotions domain (1731/6368, 27.18\%), followed by Managing My Symptoms (963/6368, $15.12 \%)$. The vast majority of My Guide participants (35/38, 92\%) accessed content related to at least one symptom within the Managing My Symptoms domain. Participants clicked on the least number of links within the Breast Cancer Medications domain $(318 / 6368,4.99 \%)$.

\section{My Health App}

Over the 6-week study period, My Health participants clicked on a total of 7167 links or webpages of study content within the app. The top 3 domains that participants most frequently accessed were Diet and Nutrition (2866/7167, 39.99\%) and Exercise (1391/7167, 19.41\%). The Preventing Diabetes and Heart Disease domain had the least number of links clicked (573/7167, 7.99\%).

\section{Study Outcomes}

Multimedia Appendix 3 and Multimedia Appendix 4 present the unadjusted means and score ranges of the study outcomes at each study assessment by high app use versus low app use of My Guide or My Health, respectively. For My Guide, scores on breast cancer well-being exceeded the minimally important difference threshold from $\mathrm{T} 1$ to $\mathrm{T} 2$ and $\mathrm{T} 1$ to $\mathrm{T} 3$ among low app users, while for My Health, scores on social well-being exceeded the minimally important difference threshold from T1 to T2 among high app users.

\section{Discussion}

This study evaluated the patterns of use of 2 culturally informed, evidence-based smartphone apps designed specifically for Latina breast cancer survivors. On average, participants used their $M y$ Guide and My Health apps for 8.66 hours and 7.28 hours, respectively. In line with prior research, our study integrated strategies to improve participant engagement, including telecoaching to promote optimal adherence to app use [52], cultural relevance and sensitivity, and specific features of the smartphone apps [53] such as ease of use, design aesthetics, and mobile phone features. Additionally, Latina breast cancer survivors spent an average of more than 1 hour per week on $M y$ Guide or My Health, which is comparable to the amount of time, if not more, patients would typically spend with an in-person counselor. These findings suggest that both apps are of interest to Latina breast cancer survivors.

The past decade has seen a significant increase in technology-assisted interventions for patients with cancer $[54,55]$. However, due to the few culturally adapted web-based interventions for patients with cancer, evaluation of the usage of these apps among minority patients has not been well-studied. The Nuevo Amanecer smartphone app for Latina breast cancer survivors, for example, is a culturally tailored smartphone app for Latina breast cancer survivors, which focuses on physical 
activity promotion [56]. Results from the Nuevo Amanecer feasibility trial revealed that women checked their physical activity tracking 4-6 times per week but click level data and total minutes spent engaging in the smartphone app were not reported as part of the study findings [56]. Notably, both $M y$ Guide and My Health demonstrated longer total durations of app use over a shorter time period compared to 2 other web-based tools for breast cancer survivors in general, which reported an average of 5.6 hours [57] and 15.2 minutes [58] of user engagement across the 4-month study time frame. Our use of telecoaching and cultural tailoring of the apps may have enhanced uptake and may explain the higher use of our smartphone app relative to that reported in previously published studies.

With the exception of employment status, sociodemographic factors did not predict app use. These findings suggest that the My Guide and My Health apps are accessible to a broad group of Latina breast cancer survivors who speak English or Spanish and have varying educational and income backgrounds, age, ancestry, marital status, and baseline HRQoL. These findings also suggest that the scalability of these apps is feasible. Women who were employed were less likely to use the My Health app, and this finding may be explained by employed breast cancer survivors having less time to devote to the app. Results also demonstrated clinically meaningful improvements in breast cancer well-being and social well-being among low users of My Guide and high users of My Health, respectively. Descriptively, low My Guide users also reported reduced symptom burden over time. However, it is unclear whether these changes are clinically meaningful due to the lack of established cutoffs for minimally important differences in symptom burden. Additional research is needed to further evaluate the associations between low app use versus high app use and improvements in HRQoL subdomains as well as to determine the optimal level of weekly app use. The finding that high My Health users reported improved social well-being over time also warrant further evaluation, as the My Health app focuses on promoting general health and healthy behaviors and does not include specific content related to social support or relationships. Follow-up interviews with participants may help contextualize study results and identify specific aspects of the intervention that were beneficial in terms of study outcomes.

Click-level data revealed that users of My Guide most frequently accessed content related to psychosocial aspects of the cancer experience followed by physical symptoms, whereas users of My Health most frequently accessed content related to nutrition and exercise. These most-clicked domains are consistent with commonly documented concerns among the general population of cancer survivors [59-61], and topics related to managing emotions, managing physical symptoms, and learning healthy lifestyle behaviors after treatment completion may signify the most relevant or engaging intervention content for Latina breast cancer survivors. Providing educational materials on nutrition and exercise may be especially important as Latinas tend to have higher rates of excess body weight and obesity when compared to their non-Latina White counterparts $[62,63]$. Women randomized to the My Guide app were most likely to click on the Managing My Emotions module. Issues regarding coping with loss of health status, bodily changes, fear of recurrence, and reduced medical oncology visits can make the transition to survivorship an emotionally challenging time [64], which may explain the greater number of clicks within the Managing My Emotions module.

The results from this study should be evaluated within the context of the study limitations. First, click-level data only provide the total number of clicks for each domain and subdomain and do not account for differences in the amount of content across the domains and subdomains. For example, the most or least accessed topics may simply reflect domains that had the most or least number of links, rather than indicating which topics had more or less engagement or interest from participants. Second, rather than the total time spent using the app, another measure of app use such as intensity or depth of engagement with the intervention (eg, proportion of specific app features used out of the total available features) [65] or some other app-related factor that we did not capture may instead be associated with study outcomes. Systematic reviews on eHealth interventions have reported a variety of metrics of app usage [25,66], including measures of frequency (eg, number of logins), duration (eg, time logged in), and activity (eg, page views, modules completed), and demonstrated that intervention outcomes may be affected by different measures of eHealth usage [25]. Third, while our sample had notable sociodemographic characteristics, including being primarily Spanish-speaking, foreign-born, and Mexican ancestry, our results may not generalize to all Latina breast cancer survivors in the United States. Additionally, this study focused on Latina breast cancer survivors who completed active treatment for breast cancer within 2 years, and the differential needs of those further into survivorship may result in different intervention effects. Future research should consider the optimal timepoint within the cancer continuum of administering the intervention as it relates to the hypothesized intervention effects. Fourth, our sample size was relatively small $(n=78)$, which limits the study findings. Lastly, our study time frame of a 6 -week intervention period plus a 2-week follow-up may have been enough to establish feasibility; however, this time frame may be too short to demonstrate efficacy. Future studies should evaluate $M y$ Guide with a larger and more diverse sample of Latina breast cancer survivors, include other objective and comprehensive measures of participant engagement or eHealth usage (eg, frequency of use, time spent on the app, activity completion) $[25,65]$, and examine whether app use is predictive of study outcomes over a longer study period.

In summary, this study contributes to the scarce research regarding eHealth supportive care interventions among Latina breast cancer survivors. The favorable rates of participant use across the study apps suggest that Latina breast cancer survivors are interested in the content delivered across both My Guide and My Health. Given the paucity of smartphone apps that have been developed for Latina patients, these click-level data may provide useful insights on the most important cancer topics for this historically understudied patient population. The click-level data provide information on the most accessed topics within the study apps, and these findings may lend insights into some of the most relevant survivorship topics for Latina breast cancer 
survivors. Furthermore, sociodemographic variables, excluding employment status, or HRQoL at study entry were not related to app use for My Guide and My Health, which suggest the potential for larger uptake among Latina breast cancer survivors. Therefore, these apps may be accessible to diverse Latina breast cancer survivors. Additional research is needed to determine the effect of eHealth use on psychosocial outcomes among Latina breast cancer survivors and whether a longer intervention time frame is needed for optimal improvements.

\section{Acknowledgments}

Research reported in this publication was supported, in part, by the National Institutes of Health's National Cancer Institute, Grant Numbers U54CA202995, U54CA202997, and U54CA203000. Authors SHB and LCB were supported by National Cancer Institute training grant T32-CA-193193. The content is solely the responsibility of the authors and does not necessarily represent the official views of the National Institutes of Health.

\section{Conflicts of Interest}

Author FJP is a paid consultant for Blue Note Therapeutics for digitizing a CBT intervention to manage anxiety and depression in cancer patients and survivors. The remaining authors report no conflicts of interest.

\section{Multimedia Appendix 1}

Domain descriptions for My Guide app and My Health app.

[DOCX File, 18 KB-Multimedia Appendix 1]

\section{Multimedia Appendix 2}

Number of clicks for each subdomain within each app domain.

[DOCX File, $20 \mathrm{~KB}-$ Multimedia Appendix 2]

\section{Multimedia Appendix 3}

Descriptive statistics of study outcomes across time for My Guide app.

[DOCX File, 17 KB-Multimedia Appendix 3]

\section{Multimedia Appendix 4}

Descriptive statistics of study outcomes across time for My Health app.

[DOCX File, $17 \mathrm{~KB}$-Multimedia Appendix 4]

\section{References}

1. American Cancer Society. Cancer facts \& figures for Hispanics/Latinos 2018-2020. Atlanta, GA: American Cancer Society Inc; 2018. URL: https://www.cancer.org/content/dam/cancer-org/research/cancer-facts-and-statistics/ cancer-facts-and-figures-for-hispanics-and-latinos/cancer-facts-and-figures-for-hispanics-and-latinos-2018-2020.pdf [accessed 2020-03-01]

2. National Cancer Institute. Cancer of the breast (invasive). United States cancer prevalence estimates.: SEER Cancer Statistics Review 1975-2017 URL: https://seer.cancer.gov/csr/1975 2017/browse csr.php?sectionSEL=4\&pageSEL=sect 04 table. 24\#b [accessed 2020-06-01]

3. Ashing-Giwa KT, Padilla GV, Bohorquez DE, Tejero JS, Garcia M. Understanding the breast cancer experience of Latina women. Journal of Psychosocial Oncology 2006;24(3):19-52. [doi: 10.1300/j077v24n03 02]

4. Eversley R, Estrin D, Dibble S, Wardlaw L, Pedrosa M, Favila-Penney W. Post-treatment symptoms among ethnic minority breast cancer survivors. Oncology Nursing Forum 2007;32(2):250-256. [doi: 10.1188/05.onf.250-256]

5. Spencer SM, Lehman JM, Wynings C, Arena P, Carver CS, Antoni MH, et al. Concerns about breast cancer and relations to psychosocial well-being in a multiethnic sample of early-stage patients. Health Psychol 1999;18(2):159-168. [doi: 10.1037/0278-6133.18.2.159]

6. Yoon J, Malin JL, Tisnado DM, Tao ML, Adams JL, Timmer MJ, et al. Symptom management after breast cancer treatment: is it influenced by patient characteristics? Breast Cancer Res Treat 2008;108(1):69-77. [doi: 10.1007/s10549-007-9580-1] [Medline: 17638071$]$

7. Fu OS, Crew KD, Jacobson JS, Greenlee H, Yu G, Campbell J, et al. Ethnicity and persistent symptom burden in breast cancer survivors. J Cancer Surviv 2009;3(4):241-250 [FREE Full text] [doi: 10.1007/s11764-009-0100-7] [Medline: 19859813]

8. Sammarco A, Konecny LM. Quality of life, social support, and uncertainty among Latina and Caucasian breast cancer survivors: a comparative study. Oncology Nursing Forum 2009;37(1):93-99. [doi: 10.1188/10.onf.93-99] 
9. Yanez B, Thompson EH, Stanton AL. Quality of life among Latina breast cancer patients: a systematic review of the literature. J Cancer Surviv 2011;5(2):191-207 [FREE Full text] [doi: 10.1007/s11764-011-0171-0] [Medline: 21274649]

10. Luckett T, Goldstein D, Butow PN, Gebski V, Aldridge LJ, McGrane J, et al. Psychological morbidity and quality of life of ethnic minority patients with cancer: a systematic review and meta-analysis. The Lancet Oncology 2011;12(13):1240-1248. [doi: 10.1016/s1470-2045(11)70212-1]

11. Moadel AB, Morgan C, Dutcher J. Psychosocial needs assessment among an underserved, ethnically diverse cancer patient population. Cancer 2007;109(2 Suppl):446-454 [FREE Full text] [doi: 10.1002/cncr.22357] [Medline: 17123273]

12. McGregor BA, Antoni MH. Psychological intervention and health outcomes among women treated for breast cancer: a review of stress pathways and biological mediators. Brain Behav Immun 2009;23(2):159-166 [FREE Full text] [doi: 10.1016/j.bbi.2008.08.002] [Medline: 18778768]

13. Antoni MH, Lechner SC, Kazi A, Wimberly SR, Sifre T, Urcuyo KR, et al. How stress management improves quality of life after treatment for breast cancer. J Consult Clin Psychol 2006;74(6):1143-1152. [doi: 10.1037/0022-006x.74.6.1143]

14. Lopez-Class M, Gomez-Duarte J, Graves K, Ashing-Giwa K. A contextual approach to understanding breast cancer survivorship among Latinas. Psychooncology 2012;21(2):115-124 [FREE Full text] [doi: 10.1002/pon.1998] [Medline: 21674680]

15. Andersen BL, Yang H, Farrar WB, Golden-Kreutz DM, Emery CF, Thornton LM, et al. Psychologic intervention improves survival for breast cancer patients: a randomized clinical trial. Cancer 2008;113(12):3450-3458 [FREE Full text] [doi: 10.1002/cncr.23969] [Medline: 19016270]

16. Antoni MH, Wimberly SR, Lechner SC, Kazi A, Sifre T, Urcuyo KR, et al. Reduction of cancer-specific thought intrusions and anxiety symptoms with a stress management intervention among women undergoing treatment for breast cancer. Am J Psychiatry 2006;163(10):1791-1797 [FREE Full text] [doi: 10.1176/ajp.2006.163.10.1791] [Medline: 17012691$]$

17. Molina Y, Thompson B, Espinoza N, Ceballos R. Breast cancer interventions serving US-based Latinas: current approaches and directions. Womens Health 2013;9(4):335-348. [doi: 10.2217/whe.13.30] [Medline: 23826775]

18. Griner D, Smith TB. Culturally adapted mental health intervention: a meta-analytic review. Psychotherapy 2006;43(4):531-548. [doi: 10.1037/0033-3204.43.4.531] [Medline: 22122142]

19. Nápoles-Springer AM, Ortíz C, O'Brien H, Díaz-Méndez M. Developing a culturally competent peer support intervention for Spanish-speaking Latinas with breast cancer. J Immigr Minor Health 2009;11(4):268-280 [FREE Full text] [doi: 10.1007/s10903-008-9128-4] [Medline: 18340533]

20. Interian A, Díaz-Martínez AM. Considerations for culturally competent cognitive-behavioral therapy for depression with Hispanic patients. Cogn Behav Pract 2007;14(1):84-97. [doi: 10.1016/j.cbpra.2006.01.006]

21. Rathod S, Gega L, Degnan A, Pikard J, Khan T, Husain N, et al. The current status of culturally adapted mental health interventions: a practice-focused review of meta-analyses. NDT 2018;Volume 14:165-178. [doi: 10.2147/ndt.s138430]

22. Duncan M, Moschopoulou E, Herrington E, Deane J, Roylance R, Jones L, SURECAN Investigators. Review of systematic reviews of non-pharmacological interventions to improve quality of life in cancer survivors. BMJ Open 2017;7(11):e015860 [FREE Full text] [doi: 10.1136/bmjopen-2017-015860] [Medline: 29187408]

23. Seiler A, Klaas V, Tröster G, Fagundes CP. eHealth and mHealth interventions in the treatment of fatigued cancer survivors: A systematic review and meta-analysis. Psychooncology 2017;26(9):1239-1253. [doi: 10.1002/pon.4489] [Medline: $\underline{28665554}$

24. Lopez M, Gonzalez-Barrera A, Patten E. Closing the digital divide: Latinos and technology adoption. Washington, D.C: Pew Hispanic Center; 2013. URL: https://www.pewresearch.org/hispanic/wp-content/uploads/sites/5/2013/03/ Latinos Social Media and Mobile Tech 03-2013 final.pdf [accessed 2020-03-01]

25. Donkin L, Christensen H, Naismith SL, Neal B, Hickie IB, Glozier N. A systematic review of the impact of adherence on the effectiveness of e-therapies. J Med Internet Res 2011;13(3):e52 [FREE Full text] [doi: 10.2196/jmir.1772] [Medline: 21821503]

26. Berry DL, Blonquist TM, Patel RA, Halpenny B, McReynolds J. Exposure to a patient-centered, Web-based intervention for managing cancer symptom and quality of life issues: impact on symptom distress. J Med Internet Res 2015;17(6):e136 [FREE Full text] [doi: 10.2196/jmir.4190] [Medline: 26041682]

27. Børøsund E, Cvancarova M, Ekstedt M, Moore SM, Ruland CM. How user characteristics affect use patterns in web-based illness management support for patients with breast and prostate cancer. J Med Internet Res 2013;15(3):e34 [FREE Full text] [doi: 10.2196/jmir.2285] [Medline: 23454601]

28. Yanez BR, Buitrago D, Buscemi J, Iacobelli F, Adler RF, Corden ME, et al. Study design and protocol for My Guide: An e-health intervention to improve patient-centered outcomes among Hispanic breast cancer survivors. Contemp Clin Trials 2018;65:61-68 [FREE Full text] [doi: 10.1016/j.cct.2017.11.018] [Medline: 29198729]

29. Yanez B, Oswald L, Baik S, Buitrago D, Iacobelli F, Perez-Tamayo A, et al. Brief culturally informed smartphone interventions decrease breast cancer symptom burden among Latina breast cancer survivors. Psychooncology 2020;29(1):195-203 [FREE Full text] [doi: 10.1002/pon.5281] [Medline: 31693265]

30. Penedo FJ, Molton I, Dahn JR, Shen B, Kinsinger D, Traeger L, et al. A randomized clinical trial of group-based cognitive-behavioral stress management in localized prostate cancer: development of stress management skills improves 
quality of life and benefit finding. Ann Behav Med 2006;31(3):261-270. [doi: 10.1207/s15324796abm3103_8] [Medline: $\underline{16700640]}$

31. Yanez B, McGinty HL, Mohr DC, Begale MJ, Dahn JR, Flury SC, et al. Feasibility, acceptability, and preliminary efficacy of a technology-assisted psychosocial intervention for racially diverse men with advanced prostate cancer. Cancer 2015;121(24):4407-4415 [FREE Full text] [doi: 10.1002/cncr.29658] [Medline: 26348661]

32. Lazarus RS, Folkman S. Transactional theory and research on emotions and coping. Eur J Pers 1987;1(3):141-169. [doi: 10.1002/per.2410010304]

33. Penedo FJ, Molton I, Dahn JR, Shen B, Kinsinger D, Traeger L, et al. A randomized clinical trial of group-based cognitive-behavioral stress management in localized prostate cancer: development of stress management skills improves quality of life and benefit finding. Ann Behav Med 2006;31(3):261-270. [doi: 10.1207/s15324796abm3103_8] [Medline: $\underline{16700640]}$

34. Yanez B, McGinty HL, Buitrago D, Ramirez AG, Penedo FJ. Cancer outcomes in Hispanics/Latinos in the United States: an integrative review and conceptual model of determinants of health. J Lat Psychol 2016;4(2):114-129 [FREE Full text] [doi: 10.1037/lat0000055] [Medline: 27429867]

35. Ganz PA, Kwan L, Stanton AL, Bower JE, Belin TR. Physical and psychosocial recovery in the year after primary treatment of breast cancer. J Clin Oncol 2011;29(9):1101-1109. [doi: 10.1200/jco.2010.28.8043]

36. Stanton AL, Snider PR. Coping with a breast cancer diagnosis: A prospective study. Health Psychol 1993;12(1):16-23. [doi: 10.1037/0278-6133.12.1.16]

37. Ashing-Giwa KT, Tejero JS, Kim J, Padilla GV, Hellemann G. Examining predictive models of HRQOL in a population-based, multiethnic sample of women with breast carcinoma. Qual Life Res 2007;16(3):413-428. [doi: 10.1007/s11136-006-9138-4] [Medline: 17279444]

38. Graves KD, Jensen RE, Cañar J, Perret-Gentil M, Leventhal K, Gonzalez F, et al. Through the lens of culture: quality of life among Latina breast cancer survivors. Breast Cancer Res Treat 2012;136(2):603-613. [doi: 10.1007/s10549-012-2291-2] [Medline: 23085764]

39. Yanez B, Maggard Gibbons M, Moreno PI, Jorge A, Stanton AL. Predictors of psychological outcomes in a longitudinal study of Latina breast cancer survivors. Psychol Health 2016;31(11):1359-1374. [doi: 10.1080/08870446.2016.1208821] [Medline: 27373454]

40. Brady MJ, Cella DF, Mo F, Bonomi AE, Tulsky DS, Lloyd SR, et al. Reliability and validity of the functional assessment of cancer therapy-breast quality-of-life instrument. J Clin Oncol 1997;15(3):974-986. [doi: 10.1200/jc0.1997.15.3.974]

41. Cella D, Hernandez L, Bonomi AE, Corona M, Vaquero M, Shiomoto G, et al. Spanish language translation and initial validation of the functional assessment of cancer therapy quality-of-life instrument. Med Care 1998;36(9):1407-1418. [doi: 10.1097/00005650-199809000-00012] [Medline: 9749663]

42. Yanez B, Pearman T, Lis CG, Beaumont JL, Cella D. The FACT-G7: a rapid version of the functional assessment of cancer therapy-general (FACT-G) for monitoring symptoms and concerns in oncology practice and research. Ann Oncol 2013;24(4):1073-1078 [FREE Full text] [doi: 10.1093/annonc/mds539] [Medline: 23136235]

43. Stanton AL, Bernaards CA, Ganz PA. The BCPT symptom scales: a measure of physical symptoms for women diagnosed with or at risk for breast cancer. J Natl Cancer Inst 2005;97(6):448-456. [doi: 10.1093/jnci/dji069] [Medline: 15770009]

44. Horowitz M, Wilner N, Alvarez W. Impact of Event Scale: a measure of subjective stress. Psychosom Med 1979;41(3):209-218. [doi: 10.1097/00006842-197905000-00004] [Medline: 472086]

45. Báguena M, Villarroya E, Beleña A, Díaz A, Roldán C, Reig R. Propiedades psicométricas de la versión española de la Escala Revisada de Impacto del Estresor (EIE-R). Análisis Modificación Conducta 2001;27(114):581-604 [FREE Full text] [doi: 10.33776/amc.v33i149.1218]

46. Wolf MS, Chang C, Davis T, Makoul G. Development and validation of the Communication and Attitudinal Self-Efficacy scale for cancer (CASE-cancer). Patient Educ Couns 2005;57(3):333-341. [doi: 10.1016/j.pec.2004.09.005] [Medline: 15893217]

47. Jean-Pierre P, Fiscella K, Freund KM, Clark J, Darnell J, Holden A, Patient Navigation Research Program Group. Structural and reliability analysis of a patient satisfaction with cancer-related care measure: a multisite patient navigation research program study. Cancer 2011;117(4):854-861 [FREE Full text] [doi: 10.1002/cncr.25501] [Medline: 20922802]

48. Chen JY, Diamant AL, Thind A, Maly RC. Determinants of breast cancer knowledge among newly diagnosed, low-income, medically underserved women with breast cancer. Cancer 2008;112(5):1153-1161 [FREE Full text] [doi: 10.1002/cncr.23262] [Medline: $\underline{18189306]}$

49. Webster K, Cella D, Yost K. The Functional Assessment of Chronic Illness Therapy (FACIT) Measurement System: properties, applications, and interpretation. Health Qual Life Outcomes 2003;1(79) [FREE Full text] [doi: 10.1186/1477-7525-1-79] [Medline: 14678568 ]

50. Yost KJ, Eton DT. Combining distribution- and anchor-based approaches to determine minimally important differences: the FACIT experience. Eval Health Prof 2005;28(2):172-191. [doi: 10.1177/0163278705275340] [Medline: 15851772]

51. Cella D, Eton DT, Lai J, Peterman AH, Merkel DE. Combining anchor and distribution-based methods to derive minimal clinically important differences on the functional assessment of cancer therapy (FACT) anemia and fatigue scales. J Pain Symptom Manage 2002;24(6):547-561. [doi: 10.1016/s0885-3924(02)00529-8] 
52. Mohr DC, Cuijpers P, Lehman K. Supportive accountability: a model for providing human support to enhance adherence to eHealth interventions. J Med Internet Res 2011;13(1):e30 [FREE Full text] [doi: 10.2196/jmir.1602] [Medline: 21393123]

53. Garnett C, Crane D, West R, Brown J, Michie S. Identification of behavior change techniques and engagement strategies to design a smartphone app to reduce alcohol consumption using a formal consensus method. JMIR Mhealth Uhealth 2015;3(2):e73 [FREE Full text] [doi: 10.2196/mhealth.3895] [Medline: 26123578]

54. Penedo FJ, Oswald LB, Kronenfeld JP, Garcia SF, Cella D, Yanez B. The increasing value of eHealth in the delivery of patient-centred cancer care. Lancet Oncol 2020(5):e240-e251. [doi: 10.1016/s1470-2045(20)30021-8]

55. Triberti S, Savioni L, Sebri V, Pravettoni G. eHealth for improving quality of life in breast cancer patients: a systematic review. Cancer Treat Rev 2019;74:1-14. [doi: 10.1016/j.ctrv.2019.01.003] [Medline: 30658289]

56. Nápoles AM, Santoyo-Olsson J, Chacón L, Stewart AL, Dixit N, Ortiz C. Feasibility of a mobile phone app and telephone coaching survivorship care planning pProgram among Spanish-speaking breast cancer survivors. JMIR Cancer 2019;5(2):e13543 [FREE Full text] [doi: 10.2196/13543] [Medline: 31290395]

57. van den Berg SW, Peters EJ, Kraaijeveld JF, Gielissen MF, Prins JB. Usage of a generic web-based self-management intervention for breast cancer survivors: substudy analysis of the BREATH trial. J Med Internet Res 2013;15(8):e170 [FREE Full text] [doi: 10.2196/jmir.2566] [Medline: 23958584]

58. Kuijpers W, Groen WG, Oldenburg HS, Wouters MW, Aaronson NK, van Harten WH. eHealth for breast cancer survivors: use, feasibility and impact of an interactive portal. JMIR Cancer 2016;2(1):e3 [FREE Full text] [doi: 10.2196/cancer.5456] [Medline: 28410178]

59. Stanton AL. Psychosocial concerns and interventions for cancer survivors. J Clin Oncol 2006;24(32):5132-5137. [doi: 10.1200/jco.2006.06.8775]

60. Ashing-Giwa KT, Padilla G, Tejero J, Kraemer J, Wright K, Coscarelli A, et al. Understanding the breast cancer experience of women: a qualitative study of African American, Asian American, Latina and Caucasian cancer survivors. Psychooncology 2004;13(6):408-428 [FREE Full text] [doi: 10.1002/pon.750] [Medline: 15188447]

61. van Londen G, Beckjord E, Dew M, Cuijpers P, Tadic S, Brufsky A. Breast cancer survivorship symptom management: current perspective and future development. Breast Cancer Manag 2013;2(1):71-81 [FREE Full text] [doi: 10.2217/bmt.12.63] [Medline: 23814614]

62. National Center for Health Statistics. Public-use data file and documentation. National Health and Nutrition Examination Survey, 2011-2012. URL: https://wwwn.cdc.gov/nchs/nhanes/continuousnhanes/default.aspx?BeginYear=2011 [accessed 2020-06-01]

63. Ogden CL, Carroll MD, Kit BK, Flegal KM. Prevalence of childhood and adult obesity in the United States, $2011-2012$. JAMA 2014;311(8):806-814 [FREE Full text] [doi: 10.1001/jama.2014.732] [Medline: 24570244]

64. Institute of Medicine, National Research Council. Psychosocial needs of women with breast cancer. In: Hewitt M, Herdman R, Holland J, editors. Meeting Psychosocial Needs of Women with Breast Cancer. Washington, D.C: National Academies Press; 2004.

65. Short CE, DeSmet A, Woods C, Williams SL, Maher C, Middelweerd A, et al. Measuring engagement in eHealth and mHealth behavior change interventions: viewpoint of methodologies. J Med Internet Res 2018;20(11):e292 [FREE Full text] [doi: 10.2196/jmir.9397] [Medline: 30446482]

66. Crutzen R, de Nooijer J, Brouwer W, Oenema A, Brug J, de Vries NK. Strategies to facilitate exposure to internet-delivered health behavior change interventions aimed at adolescents or young adults: a systematic review. Health Educ Behav 2011;38(1):49-62. [doi: 10.1177/1090198110372878] [Medline: 21189422]

\section{Abbreviations \\ CASE-cancer: Communication and Attitudinal Self-Efficacy scale for cancer \\ FACT-B: Functional Assessment of Cancer Therapy-Breast \\ FACT-G7: Functional Assessment of Cancer Therapy-General 7 items \\ HRQoL: health-related quality of life}

Edited by G Eysenbach; submitted 19.12.19; peer-reviewed by F Petracca, C Valle, G Assam Taarnh?j; comments to author 20.05.20;
revised version received 10.06.20; accepted 11.11.20; published 08.12.20
Please cite as:
Baik SH, Oswald LB, Buscemi J, Buitrago D, Iacobelli F, Perez-Tamayo A, Guitelman J, Penedo FJ, Yanez, B
Patterns of Use of Smartphone-Based Interventions Among Latina Breast Cancer Survivors: Secondary Analysis of a Pilot Randomized
Controlled Trial
JMIR Cancer $2020 ; 6(2): e 17538$
URL: $\underline{\text { http://cancer.jmir.org/2020/2/e17538/ }}$
doi: $\underline{10.2196 / 17538}$
PMID: $\underline{3289669}$


(C) Sharon H Baik, Laura B Oswald, Joanna Buscemi, Diana Buitrago, Francisco Iacobelli, Alejandra Perez-Tamayo, Judith Guitelman, Frank J Penedo, Betina Yanez. Originally published in JMIR Cancer (http://cancer.jmir.org), 08.12.2020. This is an open-access article distributed under the terms of the Creative Commons Attribution License (https://creativecommons.org/licenses/by/4.0/), which permits unrestricted use, distribution, and reproduction in any medium, provided the original work, first published in JMIR Cancer, is properly cited. The complete bibliographic information, a link to the original publication on http://cancer.jmir.org/, as well as this copyright and license information must be included. 